\title{
Dietary energy restriction reduces high-fat diet-enhanced metastasis of Lewis lung carcinoma in mice
}

\author{
Sneha Sundaram ${ }^{1}$, Lin Yan ${ }^{1}$ \\ ${ }^{1}$ U.S. Department of Agriculture, Agricultural Research Service, Grand Forks Human Nutrition Research Center, Grand Forks, \\ ND 58202, USA \\ Correspondence to: Lin Yan, email: lin.yan@ars.usda.gov.
}

Keywords: energy restriction, high-fat diet, Lewis lung carcinoma, metastasis, mice

Received: May 12,2016 Accepted: August 11,2016 Published: August 25, 2016

\section{ABSTRACT}

The objective of this study was to determine whether a reduction in energy intake ameliorated the high-fat diet-enhanced spontaneous metastasis of Lewis lung carcinoma in mice. Male C57BL/6 mice were fed the AIN93G diet, a high-fat diet or a high-fat diet with a 5\% restriction of the intake. Energy restriction reduced body adiposity and body weight, but maintained growth similar to mice fed the AIN93G diet. The high-fat diet significantly increased the number and size (cross-sectional area and volume) of metastases formed in lungs. Restricted feeding reduced the number of metastases by $23 \%$, metastatic cross-sectional area by $32 \%$ and volume by $45 \%$ compared to the high-fat diet. The high-fat diet elevated plasma concentrations of proinflammatory cytokines (monocyte chemotactic protein-1, plasminogen activator inhibitor-1, leptin), angiogenic factors (vascular endothelial growth factor, tissue inhibitor of metalloproteinase-1) and insulin. Restricted feeding significantly reduced the high-fat diet-induced elevations in plasma concentrations of proinflammatory cytokines, angiogenic factors and insulin. These results demonstrated that a reduction in diet intake by $5 \%$ reduced high-fat diet-enhanced metastasis, which may be associated with the mitigation of adiposity and down-regulation of cancer-promoting proinflammatory cytokines and angiogenic factors.

\section{INTRODUCTION}

Overweight and obesity affect cancer survival and are associated with increased mortality caused by cancer in the U.S. [1]. Recurrent and metastatic cancer remains the most devastating aspect of cancer. Obesity at the time of cancer diagnosis can be predictive of increased risk of early recurrence and metastasis [2-5]. Animal studies support the clinical observation that consumption of an obesogenic, high-fat diet increases primary tumorigenesis [6-8] and metastasis [6, 9].

Weight reduction through energy restriction is considered useful in alleviating obesity and obesityassociated cancer risk. Dietary energy restriction reduces body adiposity and body weight and improves energy metabolism [10, 11]. Furthermore, energy restriction results in favorable alterations of serum hormonal and biological factors that are related to increased risk for cancer recurrence in obese breast cancer survivors [12] and in overweight and obese women who are at increased risk of breast cancer [13]. Animal studies show that energy restriction is effective in reducing primary tumorigenesis in various models [14-16]. However, few studies have investigated the efficacy of energy restriction on metastasis.

We reported that feeding mice a high-fat diet enhances spontaneous metastasis of Lewis lung carcinoma (LLC) in lungs $[17,18]$. We hypothesized that reduction in energy intake reduces high-fat diet-enhanced metastasis. The present study tested the hypothesis by using the LLC spontaneous metastasis model in which mice were fed a high-fat diet with a 5\% reduction in intake. The rationale of choosing a 5\% restriction was to maintain growth similar to mice fed the AIN93G control diet and to avoid possible growth retardation, which possibly could attenuate the host defense against malignant aggression.

\section{RESULTS}

Unrestricted feeding of the high-fat diet increased body weight (Figure 1). The weight was different from 
that for mice fed the AIN93G diet two weeks after the initiation of the high-fat diet feeding $(p<0.05)$. The higher body weight was maintained throughout the experiment (Figure 1). Restricting the high-fat diet intake by $5 \%$ reduced body weight to levels similar to mice fed the AIN93G diet (Figure 1). The reduction was significant one week after the initiation of the restricted feeding ( $p<$ $0.05)$; the lower body weight was maintained throughout the experiment (Figure 1).

In groups receiving unrestricted feeding, the high-fat diet compared to the AIN93G diet increased the percent body fat mass by $50 \%$ (Figure $2 \mathrm{a}$ ) and correspondingly reduced the percent lean body mass by $12 \%$ (Figure $2 \mathrm{~b}$ ). Restricted feeding of the high-fat diet reduced the body fat mass by $20 \%$ (Figure 2a) and increased the body lean mass by $9 \%$ (Figure $2 \mathrm{~b}$ ). Pearson correlation analysis showed that body weight was positively correlated with body fat mass weight $(r=0.91, p<0.01)$. Unrestricted feeding of the high-fat diet elevated the lean mass weight by $4 \%$ (Figure 2c). The lean mass weight of the restricted group was $6 \%$ lower than that of the group fed the unrestricted high-fat diet, but it was similar to that of the AIN93Gfed group (Figure 2c). There was no significant difference in energy intake between groups fed the AIN93G and the high-fat diet (Figure 2d). Restricted feeding of the high-fat diet, compared to unrestricted, reduced energy intake by 9\% (Figure 2d).

Subcutaneous injection of LLC cells resulted in a primary tumor at the injection site and metastases in lungs. There was no significant difference in primary tumor weight among the three groups; the overall average was $0.34 \pm 0.01 \mathrm{~g} /$ tumor. The number of lung metastases in mice fed the unrestricted high-fat diet was $32 \%$ higher

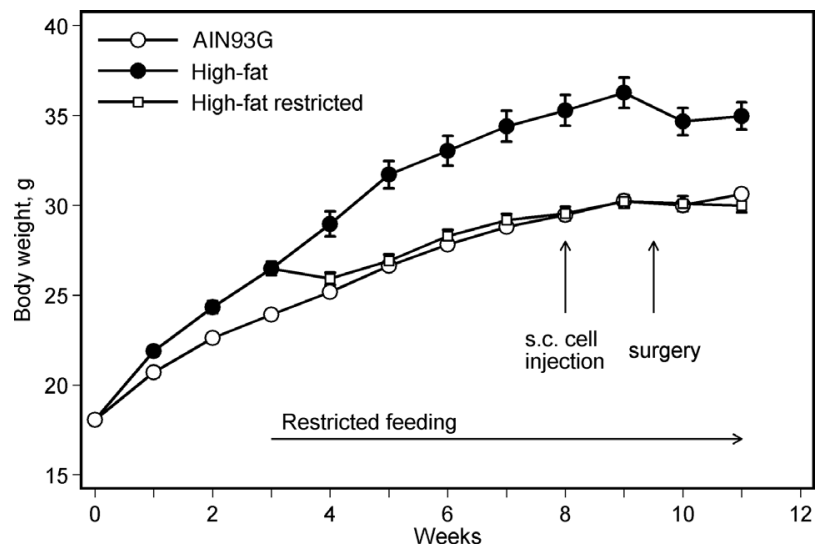

Figure 1: Restricted feeding reduces body weight in mice fed a high-fat diet. Values are means \pm SEM $(n=35-38$ per group). Mice fed the high-fat diet were heavier than those fed the AIN93G diet; the difference was significant two weeks after the initiation of experimental feeding $(p<0.05)$. Restricting diet intake by $5 \%$ reduced body weight of mice fed the high-fat diet; the difference was significant one week after the initiation of restricted feeding $(p<0.05)$. than that in mice fed the AIN93G diet (Figure 3a). Restricted compared to unrestricted intake of the high-fat diet reduced the number of metastases by $23 \%$ (Figure $3 a$ ). Compared to the AIN93G diet, the high-fat diet increased metastatic cross-sectional area by $57 \%$ (Figure $3 \mathrm{~b}$ ) and volume by $94 \%$ (Figure 3c). Restricted compared to unrestricted intake of the high-fat diet reduced the crosssectional area by $32 \%$ (Figure $3 \mathrm{~b}$ ) and the volume by $45 \%$ (Figure 3c).

There were no significant differences in plasma concentrations of MCP-1 (Figure 4a) and PAI-1 (Figure 4b) in AIN93G-fed mice with or without LLC. In LLCbearing mice, unrestricted feeding of the high-fat diet increased plasma MCP-1 by 76\% (Figure 4a) and PAI-1 by $29 \%$ (Figure 4b). Restricted compared to unrestricted feeding of the high-fat diet reduced MCP-1 by $29 \%$ (Figure 4a) and PAI-1 by 23\% (Figure 4b).

Plasma concentrations of VEGF and TIMP-1 were 27\% (Figure 4c) and 49\% (Figure 4d) higher, respectively, in LLC-bearing mice than in non-tumor-bearing mice fed the AIN93G diet. Unrestricted feeding of the high-fat diet elevated plasma VEGF by 22\% (Figure 4c) and TIMP1 by $31 \%$ (Figure 4d) in LLC-bearing mice. Restricted compared to unrestricted feeding of the high-fat diet resulted in a $23 \%$ reduction in VEGF (Figure $4 \mathrm{c}$ ) and a $22 \%$ reduction in TIMP-1 (Figure $4 \mathrm{~d}$ ).

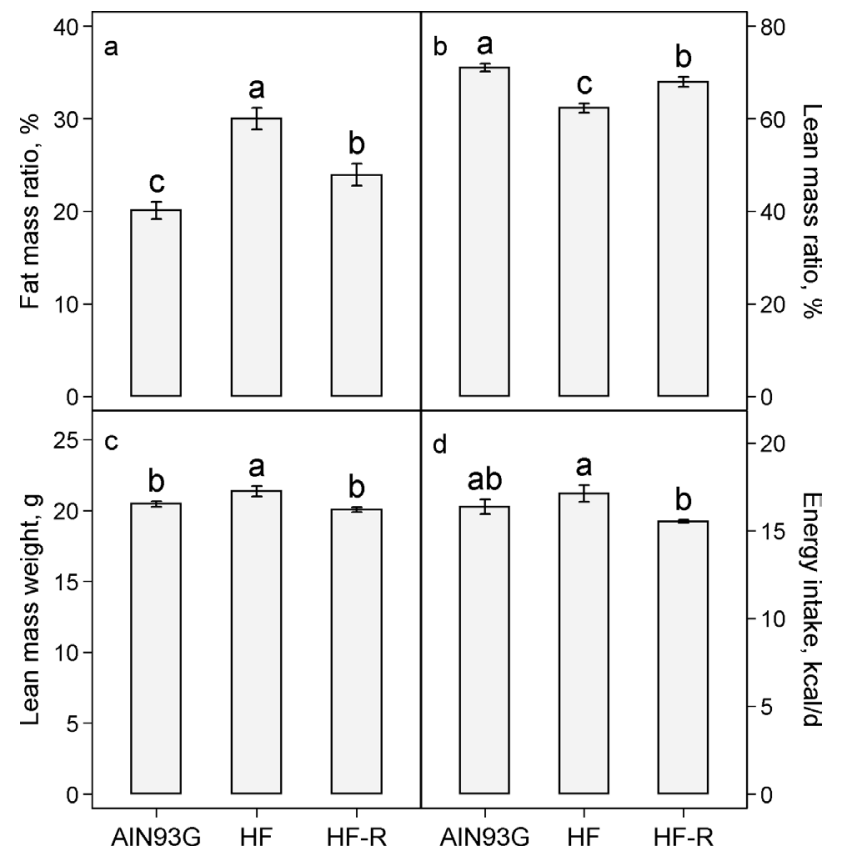

Figure 2: Effects of restricted feeding on a. fat mass: body mass ratio b. lean mass: body mass ratio c. lean mass weight and d. energy intake in mice fed a high-fat diet. Values (means $\pm \mathrm{SEM}$ ) with different letters are significantly different at $p<0.05$ ( $n=35-38$ per group, $n=6$ for energy intake). AIN93G: AIN93G diet; HF: high-fat diet; HF-R: 5\% restriction of the high-fat diet. 
There were no significant differences in plasma concentrations of leptin and insulin in AIN93G-fed mice with or without LLC (Figure 4e and 4f). In LLC-bearing mice, unrestricted feeding of the high-fat diet compared to the AIN93G diet increased plasma leptin by 3-fold (Figure $4 \mathrm{e}$ ) and insulin by $18 \%$ (Figure 4f). Restricted compared to unrestricted feeding of the high-fat diet lowered plasma leptin by $50 \%$ (Figure $4 \mathrm{e}$ ) and insulin by $9 \%$ (Figure $4 \mathrm{f}$ ).

\section{DISCUSSION}

Consistent with our previous reports [9, 17], the present study showed that feeding mice an obesogenic, high-fat diet enhances spontaneous metastasis of LLC in the lungs. A 5\% reduction in intake of this diet reduced the number and size of metastases formed in the lungs, indicating that restricted feeding reduces high-fat dietenhanced metastasis.

Reduction in pulmonary metastasis by restricted feeding is accompanied with reductions in body fat mass and concentrations of proinflammatory cytokines in plasma. Adipose tissue is an endocrine organ that produces proinflammatory cytokines. For example, feeding mice a high-fat diet significantly elevated concentrations of MCP-1 [19] and PAI-1 in adipose tissue [18]. Elevation

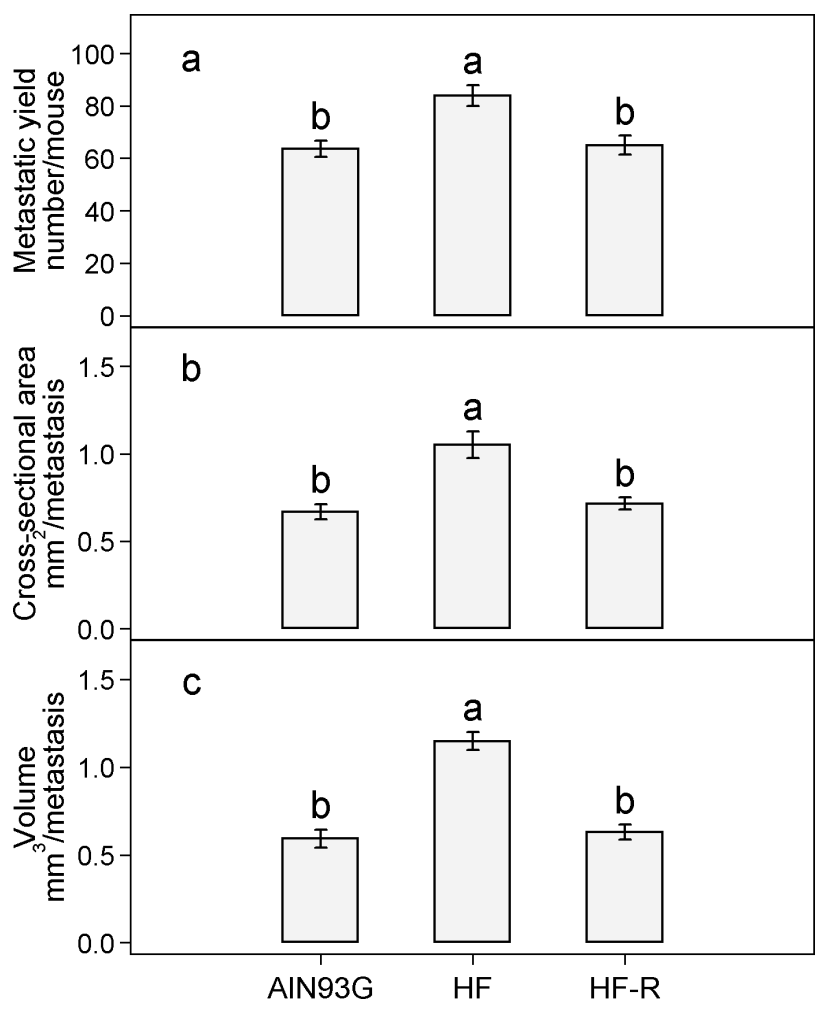

Figure 3: Restricted feeding reduces the a. number $b$. cross-sectional area and c. volume of lung metastases in mice fed the high-fat diet. Values (means \pm SEM) with different letters are significantly different at $p<0.05(n=34-36$ per group). AIN93G: AIN93G diet; HF: high-fat diet; HF-R: 5\% restriction of the high-fat diet. in proinflammatory cytokines is associated with cancer progression [20, 21]. Knocking out MCP-1 [19] or PAI1 genes from mice [18] reduces high-fat diet-enhanced metastasis. A reduction in body adiposity may lead to a decreased production of proinflammatory cytokines including MCP-1 and PAI-1, which may be responsible, at least partly, for the anti-metastatic effects of the restricted feeding.

Angiogenesis plays an important role in tumorigenesis and transporting metastatic cells to target organs. Both VEGF and TIMP-1 are potent angiogenic factors. We previously found that plasma concentrations of VEGF and TIMP-1 are elevated in mice with LLC metastases, and they are further elevated by feeding mice a high-fat diet $[18,19]$. In the present study, the increases in plasma concentrations of VEGF and TIMP-1 with high-fat diet-enhanced metastasis indicate a stimulation of angiogenesis during LLC spread and growth. Restricted feeding of the high-fat diet significantly reduced concentrations of VEGF and TIMP-1, which suggests a down-regulation of angiogenesis. This down-regulation may contribute to the attenuation of LLC metastatic progression by the restricted feeding.

The lower concentrations of leptin and insulin in plasma of mice receiving restricted feeding were likely the result of reduced adiposity. Leptin and insulin

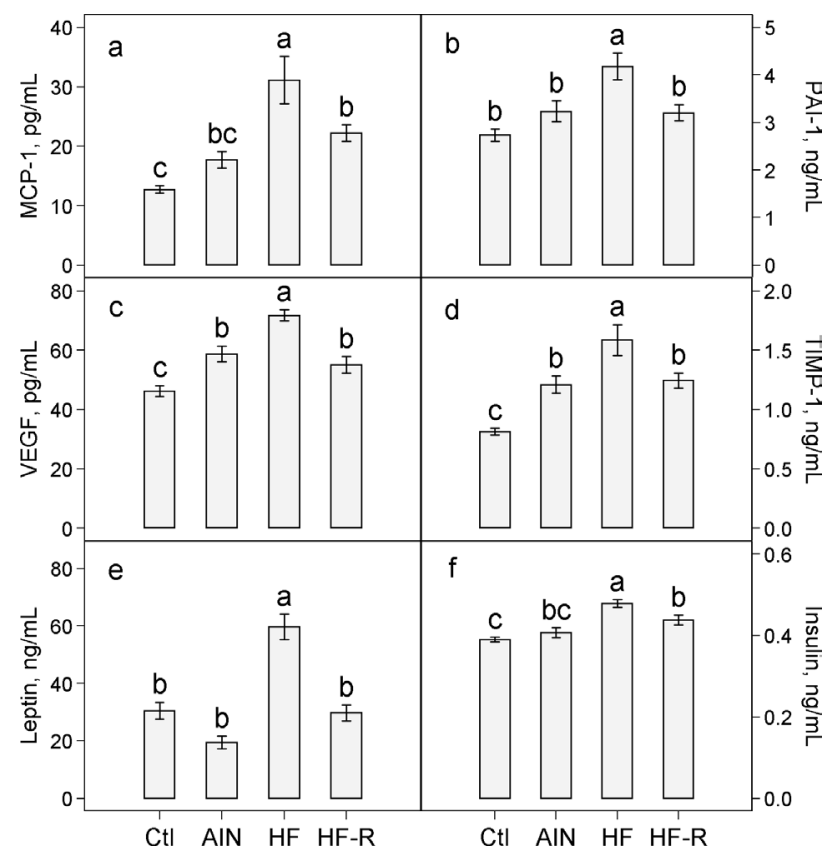

Figure 4: Effects of restricted feeding on plasma concentrations of a. MCP-1 b. PAI-1 c. VEGF d. TIMP1 e. leptin and $f$. insulin in mice fed the high-fat diet. Values (means \pm SEM) with different letters are significantly different at $p<0.05$ ( $n=10$ per group). Ctl: non-tumor-bearing mice fed the AIN93G diet; AIN: AIN93G diet; HF: High-fat diet; HF-R: $5 \%$ restriction of the high-fat diet. 
actively participate in energy metabolism and their elevations in blood correlate with metabolic disturbance in rodent models of obesity [22, 23]. Furthermore, leptin is angiogenic during tumorigenesis [24], and insulin is involved in type- 2 diabetes-mediated mammary tumor progression in mice [25]. Reductions in leptin and insulin indicate that restricted feeding may attenuate metabolic disturbance by intake of the high-fat diet, and such an action may contribute to the anti-metastatic effects of restricted feeding.

Energy restriction, ranging from $20 \%$ to $40 \%$, has been used to induce weight loss in rodent models in cancer prevention research [15, 26-28]. Previously, we found that a $30 \%$ restriction of high-fat diet intake halted growth and a $20 \%$ restriction significantly retarded growth of $\mathrm{C} 57 \mathrm{BL} / 6$ mice, while a $7 \%$ restriction resulted in a slightly lower but similar growth to mice fed the AIN93G diet (unpublished data). Thus, we chose to restrict the intake by $5 \%$ because food intake should not be reduced to the point where minimum energy needs for physiological growth and maintenance of animals cannot be met. Energy restriction is defined as a reduction in energy intake without malnutrition [29]. Growth retardation due to malnutrition because of energy deprivation should be distinguished from weight and adiposity loss due to energy restriction. This is particularly important in cancer prevention research. Malignant growth competes against the host for nutrients to support its rapid progression. Caution should be taken to avoid energy deprivation or insufficiency in models of weight loss and maintenance, which may bias the results and their interpretation.

In summary, results from this study showed that restricting the high-fat diet intake by $5 \%$, which reduced body adiposity and body weight but maintained normal growth of mice, reduced high-fat diet-enhanced spontaneous metastasis. Inhibition of metastasis by restricted feeding is likely through mechanisms of rebalancing metabolic homeostasis by reducing adipogenesis and downregulating its associated production of cancer-promoting proinflammatory cytokines and angiogenic factors. Furthermore, it suggests that dietary energy restriction, by reducing body adiposity and maintaining a healthy body weight, may reduce the severity of occurrence and metastasis in overweight or obese cancer patients after treatment of primary cancer, and thus improve prognosis and quality of life.

\section{MATERIALS AND METHODS}

\section{Animals and diets}

Three-week-old male C57BL/6 mice (Harlan, Madison, WI) were maintained in a pathogen-free room with a 12:12-hour light/dark cycle and a temperature of 22 $\pm 1^{\circ} \mathrm{C}$. Three diets were used in this study, the AIN93G diet
[30] containing $16 \%$ or $45 \%$ (high-fat diet) of energy from corn oil, or the high-fat diet for the $5 \%$ restricted feeding in that the nutrient density was adjusted to be equivalent to that of the high-fat diet for the unrestricted feeding (Table 1). All diets were powder diets; they were stored at $-20^{\circ} \mathrm{C}$ until feeding. Gross energy of each diet (Table 1) was analyzed by using oxygen bomb calorimetry (Model 6200, Oxygen Bomb Calorimeter, Parr Instrument, Moline, IL).

\section{Lewis lung carcinoma cells}

Lewis lung carcinoma (LLC) cell line, a variant that metastasizes to lungs [31], was obtained from Dr. Pnina Brodt, McGill University, Montreal, Quebec, Canada. The cells were cultured with RPMI-1640 medium containing $10 \%$ heat-inactivated fetal bovine serum and maintained in a humidified atmosphere of $5 \% \mathrm{CO}_{2}$ in air at $37^{\circ} \mathrm{C}$. Cells used for animal studies were in vivo-selected once [9]. The cells were monitored for phenotype by microscopic examination of cell morphology, proliferation properties by growth curve analysis and metastatic capability by injecting cells subcutaneously into mice and examining metastatic formation in lungs. Cells were free of mycoplasma based on Hoechst DNA staining and direct culture tests (performed by American Type Cell Collection, Manassas, VA). These assessments showed that cell identity and metastatic behavior were similar to those of original stocks from the institution providing the cell line.

\section{Experimental design}

This study was approved by the Institutional Animal Care and Use Committee of the U.S. Department of Agriculture, Agricultural Research Service, Grand Forks Human Nutrition Research Center. The procedures followed the National Institutes of Health guidelines for the care and use of laboratory animals [32].

After acclimation with the AIN93G diet for one week, mice were randomly assigned into two groups and fed the AIN93G $(n=36)$ and the high-fat diet $(n=73)$, respectively. Food intake measurements ( $n=6$ per group) were initiated two weeks later when significant differences in body weight occurred between the two groups. At week three, mice fed the high-fat diet were divided into two groups; one remained on unrestricted access to the $\operatorname{diet}(n=38)$, and the other was fed $95 \%$ of the amount that the unrestricted group consumed in the previous day $(n=35)$. To avoid food loss by spilling, diet was provided to the restricted group twice daily, one half at 8:00 a.m. and the other half at 4:00 p.m. Body composition was assessed in conscious, immobilized mice one week before cancer cell injection by using quantitative magnetic resonance imaging (Echo whole-body composition analyzer, Model 100, Echo Medical System, Houston, TX). Five weeks after the initiation of the restricted feeding, mice were subcutaneously injected with $2.5 \times 10^{5}$ viable LLC cells per mouse into the lower dorsal region. The resulting 
Table 1: Composition of diets

\begin{tabular}{|c|c|c|c|}
\hline & AIN93G & High-fat & $\begin{array}{c}\text { High-fat for } 5 \% \text { restricted } \\
\text { feeding }\end{array}$ \\
\hline Ingredient & $\mathrm{g} / \mathrm{kg}$ & $\mathrm{g} / \mathrm{kg}$ & $\mathrm{g} / \mathrm{kg}$ \\
\hline Corn Starch & 397.5 & 40.2 & 22.6 \\
\hline Casein & 200 & 239.4 & 252.5 \\
\hline Dextrin & 132 & 239.4 & 239.4 \\
\hline Sucrose & 100 & 119.7 & 119.7 \\
\hline Corn oil & 70 & 241.1 & 242.5 \\
\hline Cellulose & 50 & 59.8 & 59.8 \\
\hline AIN93 mineral mix & 35 & 41.9 & 44.0 \\
\hline AIN93 vitamin mix & 10 & 12 & 12.6 \\
\hline L-Cystine & 3 & 3.6 & 3.8 \\
\hline Choline bitartrate & 2.5 & 3 & 3.1 \\
\hline$t$-Butylhydroquinone & 0.014 & 0.02 & 0.02 \\
\hline Total & 1000 & 1000 & 1000 \\
\hline Energy & $\%$ & $\%$ & $\%$ \\
\hline Protein & 20 & 20 & 21.3 \\
\hline Fat & 16 & 45 & 45.2 \\
\hline Carbohydrate & 64 & 35 & 33.5 \\
\hline Gross energy $\mathrm{kcal} / \mathrm{g}^{\mathrm{a}}$ & $4.4 \pm 0.1$ & $5.3 \pm 0.1$ & $5.3 \pm 0.1$ \\
\hline
\end{tabular}

${ }^{a}$ Values are means \pm SEM of five samples analyzed from each diet.

subcutaneous tumor was resected surgically 10 days later when it was approximately one $\mathrm{cm}$ in diameter. Following surgery, mice were maintained on their respective diets for an additional 10 days. Mice fed the AIN93G diet but not injected with cancer cells served as controls to assess changes in plasma concentrations of cytokines and related biomarkers due to metastasis in LLC-bearing mice fed the AIN93G diet. Mice with recurrence after surgery were excluded from the study.

At termination, mice were intraperitoneally injected with a mixture of ketamine/xylazine. Lungs were harvested and fixed with Bouin's solution. The number of pulmonary metastases was counted [33] and the cross-sectional area and the volume of each metastasis were analyzed [34] by using a cameraequipped stereomicroscope and ImagePro-Plus software (Media Cybernetics, Silver Spring, MD). The crosssectional area of a metastasis was defined as the surface area of the lung metastasis. The volume was estimated by assuming that the metastasis was spherical and using its average diameter [34]. The average diameter was the average measured at two degree intervals joining two outline points and passing through the centroid. Plasma was collected and stored at $-80^{\circ} \mathrm{C}$ for quantifying proinflammatory cytokines, angiogenic factors and insulin.

\section{Concentrations of cytokines, angiogenic factors and insulin in plasma}

Sandwich enzyme-linked immunosorbent assay (ELISA) kits were used to quantify plasma concentrations of proinflammatory cytokines (leptin, monocyte chemotactic protein-1 (MCP-1) and plasminogen activator inhibitor-1 (PAI-1)), angiogenic factors (vascular endothelial growth factor (VEGF) and tissue inhibitor of metalloproteinase-1 (TIMP-1)) and insulin following manufacturers' protocols. Leptin, MCP-1, PAI-1, VEGF and TIMP-1 ELISA kits were obtained from R\&D Systems (Minneapolis, MN), and the insulin kit was from Mercodia (Winston-Salem, NC). Samples were read within the linear range of the assay, and the accuracy of the analysis was confirmed by the controls provided in each kit.

\section{Statistical analyses}

One-way analysis of variance (ANOVA) and Tukey contrasts were used to compare differences among the groups. Pearson correlation was performed between body weight and body fat mass weight. A mixed model ANOVA with mouse as the random blocking factor was used to compare differences in size of metastases (cross- 
sectional area and volume) in mice fed different diets. All data are presented as means \pm standard error of the mean (SEM). Differences with a $p$ value of 0.05 or less are considered significant. All analyses were performed by using SAS software (version 9.4, SAS Institute, Cary, NC).

\section{ACKNOWLEDGMENTS}

The authors gratefully acknowledge the assistance of the following staff of the Grand Forks Human Nutrition Research Center: Lana DeMars and Kay Keehr for technical support, LuAnn Johnson for advice in statistical analysis, Dr. Forrest Nielsen for providing valuable input in manuscript preparation and revision, James Lindlauf for preparing experimental diets and vivarium staff for providing high-quality animal care.

\section{NOTES}

The U.S. Department of Agriculture, Agricultural Research Service, Plains Area is an equal opportunity/ affirmative action employer and all agency services are available without discrimination. Mention of trade names or commercial products in this article is solely for providing specific information and does not imply recommendation or endorsement by the U.S. Department of Agriculture.

\section{CONFLICTS OF INTEREST}

The authors have declared that no competing interests exist.

\section{GRANT SUPPORT}

Funding for this work was provided by the U.S. Department of Agriculture, Agriculture Research Service, Research Project 3062-51000-050-00D.

\section{REFERENCES}

1. Calle EE, Rodriguez C, Walker-Thurmond K, Thun MJ. Overweight, obesity, and mortality from cancer in a prospectively studied cohort of U.S. adults. New Eng J Med. 2003; 348:1625-1638.

2. Daniell HW. Increased lymph node metastases at mastectomy for breast cancer associated with host obesity, cigarette smoking, age, and large tumor size. Cancer. 1988; 62:429-435.

3. Loi S, Milne RL, Friedlander ML, McCredie MR, Giles GG, Hopper JL, Phillips KA. Obesity and outcomes in premenopausal and postmenopausal breast cancer. Cancer Epidemiol Biomarkers Prev. 2005; 14:1686-1691.
4. Bassett WW, Cooperberg MR, Sadetsky N, Silva S, DuChane J, Pasta DJ, Chan JM, Anast JW, Carroll PR, Kane CJ. Impact of obesity on prostate cancer recurrence after radical prostatectomy: data from CaPSURE. Urology. 2005; 66:1060-1065.

5. Amling CL, Riffenburgh RH, Sun L, Moul JW, Lance RS, Kusuda L, Sexton WJ, Soderdahl DW, Donahue TF, Foley JP, Chung AK, McLeod DG. Pathologic variables and recurrence rates as related to obesity and race in men with prostate cancer undergoing radical prostatectomy. J Clin Oncol. 2004; 22:439-445.

6. Rose DP, Connolly JM, Meschter CL. Effect of dietary fat on human breast cancer growth and lung metastasis in nude mice. J Natl Cancer Inst. 1991; 83:1491-1495.

7. Kimura Y, Sumiyoshi M. High-fat, high-sucrose, and highcholesterol diets accelerate tumor growth and metastasis in tumor-bearing mice. Nutr Cancer. 2007; 59:207-216.

8. Sumiyoshi M, Kimura Y. Effects of a High-Fat or HighSucrose Diet on Ultraviolet B Irradiation-Induced Carcinogenesis and Tumor Growth in Melanin-Possessing Hairless Mice. Nutr Cancer. 2016:1-13.

9. Yan L, Demars LC. Effects of dietary fat on spontaneous metastasis of Lewis lung carcinoma in mice. Clin Exp Metastasis. 2010; 27:581-590.

10. Foster-Schubert KE, Alfano CM, Duggan CR, Xiao L, Campbell KL, Kong A, Bain CE, Wang CY, Blackburn GL, McTiernan A. Effect of diet and exercise, alone or combined, on weight and body composition in overweightto-obese postmenopausal women. Obesity (Silver Spring). 2012; 20:1628-1638.

11. Villareal DT, Chode S, Parimi N, Sinacore DR, Hilton T, Armamento-Villareal R, Napoli N, Qualls C, Shah K. Weight loss, exercise, or both and physical function in obese older adults. N Engl J Med. 2011; 364:1218-1229.

12. Rock CL, Pande C, Flatt SW, Ying C, Pakiz B, Parker BA, Williams K, Bardwell WA, Heath DD, Nichols JF. Favorable changes in serum estrogens and other biologic factors after weight loss in breast cancer survivors who are overweight or obese. Clin Breast Cancer. 2013; 13:188-195.

13. Ong KR, Sims AH, Harvie M, Chapman M, Dunn WB, Broadhurst D, Goodacre R, Wilson M, Thomas N, Clarke RB, Howell A. Biomarkers of dietary energy restriction in women at increased risk of breast cancer. Cancer Prev Res (Phila). 2009; 2:720-731.

14. Thompson HJ, McGinley JN, Spoelstra NS, Jiang W, Zhu Z, Wolfe P. Effect of dietary energy restriction on vascular density during mammary carcinogenesis. Cancer Res. 2004; 64:5643-5650

15. Matsuzaki J, Yamaji R, Kiyomiya K, Kurebe M, Inui H, Nakano Y. Implanted tumor growth is suppressed and survival is prolonged in sixty percent of food-restricted mice. J Nutr. 2000; 130:111-115.

16. Sundaram S, Le TL, Essaid L, Freemerman AJ, Huang MJ, Galanko JA, McNaughton KK, Bendt KM, Darr DB, 
Troester MA, Makowski L. Weight loss reversed obesityinduced HGF/c-Met pathway and basal-like breast cancer progression. Front Oncol. 2014; 4:175.

17. Yan L, Combs GFJ. Consumption of a high-fat diet abrogates inhibitory effects of methylseleninic acid on spontaneous metastasis of Lewis lung carcinoma in mice. Carcinogenesis. 2014; 35:2308-2313.

18. Yan L, DeMars LC. Effects of a high-fat diet on spontaneous metastasis of Lewis lung carcinoma in plasminogen activator inhibitor-1 deficient and wild-type mice. PLoS ONE. 2014; 9:e110869.

19. Yan L, Sundaram S. Monocyte chemotactic protein-1 deficiency reduces spontaneous metastasis of Lewis lung carcinoma in mice fed a high-fat diet. Oncotarget. 2016; 7:24792-24799. doi: 10.18632/oncotarget.8364.

20. Lebrecht A, Grimm C, Lantzsch T, Ludwig E, Hefler L, Ulbrich E, Koelbl H. Monocyte chemoattractant protein-1 serum levels in patients with breast cancer. Tumour Biol. $2004 ; 25: 14-17$

21. Janicke F, Schmitt M, Pache L, Ulm K, Harbeck N, Hofler $\mathrm{H}$, Graeff H. Urokinase (uPA) and its inhibitor PAI-1 are strong and independent prognostic factors in nodenegative breast cancer. Breast Cancer Res Treat. 1993; 24:195-208.

22. Yan L, Graef GL, Claycombe KJ, Johnson LK. Effects of voluntary running and soy supplementation on diet-induced metabolic disturbances and inflammation in mice. J Agric Food Chem. 2013; 61:9373-9379.

23. Fenton JI, Nunez NP, Yakar S, Perkins SN, Hord NG, Hursting SD. Diet-induced adiposity alters the serum profile of inflammation in C57BL/6N mice as measured by antibody array. Diabetes Obes Metab. 2009; 11:343-354.

24. Rene Gonzalez R, Watters A, Xu Y, Singh UP, Mann DR, Rueda BR, Penichet ML. Leptin-signaling inhibition results in efficient anti-tumor activity in estrogen receptor positive or negative breast cancer. Breast Cancer Res. 2009; 11:R36.

25. Fierz Y, Novosyadlyy R, Vijayakumar A, Yakar S, LeRoith D. Insulin-sensitizing therapy attenuates type 2 diabetesmediated mammary tumor progression. Diabetes. 2010; 59:686-693.
26. Mai V, Colbert LH, Berrigan D, Perkins SN, Pfeiffer R, Lavigne JA, Lanza E, Haines DC, Schatzkin A, Hursting SD. Calorie restriction and diet composition modulate spontaneous intestinal tumorigenesis in Apc(Min) mice through different mechanisms. Cancer Res. 2003; 63:1752-1755.

27. Yakar S, Nunez NP, Pennisi P, Brodt P, Sun H, Fallavollita L, Zhao H, Scavo L, Novosyadlyy R, Kurshan N, Stannard B, East-Palmer J, Smith NC, et al. Increased tumor growth in mice with diet-induced obesity: impact of ovarian hormones. Endocrinology. 2006; 147:5826-5834.

28. Zhu Z, Jiang W, McGinley JN, Price JM, Gao B, Thompson HJ. Effects of dietary energy restriction on gene regulation in mammary epithelial cells. Cancer Res. 2007; 67:12018-12025.

29. Weindruch R, Sohal RS. Seminars in medicine of the Beth Israel Deaconess Medical Center. Caloric intake and aging. N Engl J Med. 1997; 337:986-994.

30. Reeves PG, Nielsen FH, Fahey GCJ. AIN-93 purified diets for laboratory rodents: final report of the American Institute of Nutrition ad hoc writing committee on the reformulation of the AIN-76A rodent diet. J Nutr. 1993; 123:1939-1951.

31. Brodt P. Characterization of two highly metastatic variants of Lewis lung carcinoma with different organ specificities. Cancer Res. 1986; 46:2442-2448.

32. Institute for Laboratory Animal Research. (2011). Guide for the Care and Use of Laboratory Animals. (Washington, D.C.: National Academies Press).

33. Fidler IJ. (1978). General considerations for studies of experimental cancer metastasis. In: Busch H, ed. Methods in Cancer Research. (New York: Academic Press), pp. 399-439.

34. Welch DR, Neri A, Nicolson GL. Comparison of 'spontaneous' and 'experimental' metastasis using rat 13726 mammary adenocarcinoma metastatic cell clones. Invasion Metastasis. 1983; 3:65-80. 